\title{
Landscape Quality Valuation for its Preservation and Treasuring
}

\author{
Domenico Enrico Massimo ${ }^{1, a}$, Mariangela Musolino ${ }^{1, b}$ \\ Antonino Barbalace ${ }^{2, \mathrm{c}}$ and Cinzia Fragomeni ${ }^{1, \mathrm{~d}}$ \\ ${ }^{1} 25$ Via Melissari, 89124 Reggio Calabria, Italy \\ ${ }^{2}$ MIT, 265 Massachusetts Avenue, Building N52, Cambridge, MA 02139, Usa \\ amassimo@unirc.it, ${ }^{b}$ mariangela.musolino@unirc.it, 'barbalac@mit.edu, ${ }^{\mathrm{d}}$ cinziaf@mit.edu
}

\begin{abstract}
Keywords: Landscape Quality Appraisal, Landscape element Assessment, Multi Criteria Valuation, Land Transformation, Landscape Planning.
\end{abstract}

\begin{abstract}
Pollution, environmental disruption, oversized urban development and infrastructure new construction jeopardize landscape integrity and people's quality of life. Research deals with the landscape protection and enhancement providing governments and decision makers with a comprehensive Decision Support System to assess the quality of natural and cultural heritage and address planning measures and policy actions for landscape treasuring [1]. Research set-up a methodology relying upon GIS tools, to spatially discover, detect and define landscape units, so called "Landscape Elements" ("Elementi di Paesaggio", EdP), along with their endowment such as natural, ecological, historic, cultural, and urban resources. Then evaluate them through a multi criteria analysis tool set-up by the research team and integrated with a GIS. Research developed a Case Study in the European Mediterranean Basin, validating the whole census system and the performance and support of valuation tools [2,3]. Results achieved open the possibility to generalize the prototype application at the regional, country and federation levels and therefore support the planning implementation for landscape enhancement.
\end{abstract}

\section{Background}

Countries are increasingly subjected to the pressure of "urban sprawl", infrastructure densification, soil water - proofing, construction of new pipeline systems, whose "unplanned" localizations and combined cumulative negative impacts are causing land consumption and progressive ecological degradation (for a summary: $[4,5,6,7,8]$ ).

As a result, the threat to agricultural and forestry areas, as well as to natural and agrarian landscapes, full of qualities, risks to turn them into unproductive and dangerous semi-urbanized lands.

To cope with this ongoing dramatic change, states, governments, international organizations, as well as local and regional communities, have gradually built-up a framework or system of actions for the protection and improvement of environment, territories, soils, agricultural areas, forests; open land.

\section{General objective of the research}

Research goal is to outline and apply the planning frameworks to protect and treasure Landscape and local resources, by designing and planning specific operational phases and also by developing valuation and appraisal tools. Both support programs devoted to mitigate the negative landscape and environmental impacts (such as the further destruction or decay of farming and forest areas) due to unplanned, therefore uncoordinated, human actions, like new construction and expansions.

Research is addressed to all community members and institutional actors to contribute and foster-up:

(a) new policies and strategies to prevent the destruction of arable and forest resources, promoting the treasuring of agrarian and natural landscapes;

(b) new ways to ameliorate construction of building and infrastructures with smaller impact on the environment to preserving the Landscape Elements. 
These actions and features are implemented and tested in a specific and real world Case Study introduced below.

\section{Landscape Unit}

A spatial information and valuation system has been built up to provide a possible answer to questions that are historically unresolved and related to the construction of a systematic detection and knowledge of Landscape Areas (AdP), Landscape Units (UdP) as well as a multi-dimensional valuation of Landscape Elements ("Elementi di Paesaggio", EdP). Landscape Units are the basis of geographic management of Landscape resources and elements. Information is derived from objective basis, both documentary and directly surveyed.

The methodology developed indicates the criteria and operational stages for the identification of the AdP and related UdP, through a systemic and relational vision, with the "prevalence" of the morphological factors.

Therefore, the boundaries of these areas derive from the interweaving of historical, geographical, hydro-geomorphological, ecological, settlement, and identity features.

The result obtained with this heuristic-intuitive methodology consists in the identification and interpretation of landscape areas in which some elements $\backslash$ factors have peculiar characteristics, while others are less "qualitative". All that has the purpose of a brief identification of areas as homogeneous landscape units.

The discovery of excellent historical topographic maps led to a breakthrough in the accounts of landscape resources allowing the verification and valuation of their existence on the basis of objective data. The result is a GeoDataBase within the General System of Valuation (SGV) in which all the landscape resources are documented and articulated in categories and sub-categories. The GIS tools allow to create layers of Landscape Elements to be then enriched with information related to their location, i.e., within the AdP and $\operatorname{UdP}$ (Fig. 1,2).

\section{Methodological framework}

A framework has been devoted for protection and enhancement of paysage resources and Landscapes Elements. The devoted framework is structured as an integrated tool focused to support landscape planning. The tool is part of a complex General Valuation System (SGV) for valuation and appraisal $[9,10]$ and it contains logical sequences that foresee specific operational functions, including those summarized below.

- Knowledge and total inventory function. Data collection on the field and building-up of a complete total knowledge (so far fragmented and unsystematic) of resources, i.e. of agrarian, landscape and environmental assets, in the territories.

- Geographic information function. Accurate spatialization and geo-referencing of the above information. It directly support landscape and urban planning, avoiding the overlapping of new constructions in sensitive areas, characterized by landscape high values.

- Preventive conservation function. Outline through a rigorous buffering the Landscape Elements and the agricultural areas embodying highest values to be preserved.

- Planning function. Transferring of all information (produced by the research) in the institutional tools of landscape preservation planning. It formalizes the existence and location of Landscape Elements to prevent conflicts and overlaps with further new urban development and additional spread. Disseminating this knowledge to society and to individual citizens, via the Landscape Networks.

- Enhancement and promotion function. Create the institutional conditions as well as the operational and entrepreneurial milieu to promote actions of total enhancement of the Landscape Elements inversely proportional to their embodied and incorporated values and graduated as follows: preservation; existence; indirect use; subsidiary direct fruition, use. 


\section{Action for landscape knowledge and preservation}

The mitigation of the "aggression" of new construction against the environment must therefore be one of the goals of landscape planning along with the enhancement of specific resources.

These objectives push the research to provide conceptual and operational tools to as follows.

- Classify and taxonomize landscapes components per homogeneous clusters and categories. This by surveying all landscape elements and features and organizing them in a total systematic inventory.

- Define and outline homogeneous landscape areas (so called "Unità di Paesaggio", UdP) according to shared criteria.

- Comparatively assess Landscape Elements with ordinal approach through specific Multi Criteria Analysis tools. Derive hierarchical ranking of resources to support the deployment of actions to actively protect and enhance them.

- Outline an agenda for treasuring of single elements and their correspondent clusters.

\section{Multi Criteria Analysis and GIS system}

Landscape Elements can be articulated in different categories. In order to promote their comparative protection and enhancement it is necessary to estimate their ranking value and attractiveness per homogeneous clusters. From the ranking it derives the priorities of protection according to their intrinsic values. Then, valuation and information tools are strongly needed. Valuation is the only approach that allows outlining an agenda of action based on the actual characteristics and quality levels of the Elements.

The valuation process to support preservation, protection and enhancement of resources is based upon a multi criteria tool allowing valuators and assessors to analyze each Landscape Element as a bundle of characteristics. Each characteristic is intended as a criterion for valuation. Assessors assign an ordinal score for each characteristics of each Landscape Element, building up a matrix $[11,12]$. It is the basis to manipulate ordinal scores applying multi-dimensional algorithms of multi criteria approaches. Result of the valuation methodology is an ordinal rank order of each similar element analyzed in the set. It can help to figure-out priorities in preservation and project for Landscape treasuring.

Valuation methodology is articulated in the following steps.

\subsection{Identification-census of the resources in a specific area}

The Landscape Elements are researched, detected, counted and valuated according to their relevance and subsequently categorized or grouped in homogeneous clusters for multi criteria valuation and ordinal ranking for their protection and enhancement.

The total census on the area provides quantitative assessment and numerical digits of entities, resources, objects. This becomes an element of measurement to:

- estimate and derive the intensity of Landscape and Elements features in the space;

- identify areas with particular quality to be protected;

- set up the knowledge to derive the perimeter - boundaries of Landscape Areas (AdP) and Landscape Units (UdP).

- set up goals to pursue landscape quality.

\subsection{Identification of AdP and UdP}

Potentials have been identified to promote a sustainable treasuring of Landscape Elements through: ecological conservation of Earth values; compatible activities harmonized with imperative protection. 


\subsection{Sustainable enhancement}

In an articulated process applied to a complex topic (as Landscape) the valuation approaches and instruments are necessarily diversified and of different types such as the following.

- Detecting and enlisting resources and categories.

- Accounting single element in general and categorical lists.

- Perform heuristic initial assessment of embodied quality in each resource.

- Play multi criteria valuation for most important Landscape Elements.

- Estimate potential touristic impact of resource treasuring.

\subsection{Operative Tools}

Operative tools are articulated as follows.

1. Definition of different types of landscape resources and elements is done with the systemic approach of Taxonomy.

2. Real census on the field is done with an accounting tool named "Taxonomic Inventory", which populates the systematic scientific structure of preview introduce Taxonomy.

3. Spatial system of knowledge and protection with the buffering is done with the information tool of the GeoDataBase.

4. Specific valuation system to estimate the "values" in the territories, to support landscape planning, belongs to the broader integrated "General Information System for Valuation, SGV", which is an economic and urban tool for the territorial government of large areas (Massimo, Musolino, Barbalace, 2006). The analytical estimate with multiple criteria is done by adopting one of most reliable approaches, algorithms and related software. Among them, there are the Analytical Hierarchy Process (AHP) by Thomas L. Saaty [13] and the Dominant Regime Method (DRM) by Peter Nijkamp $[14,15,16]$. Census derives a high number of Landscape Elements to be valuated with multiple criteria, and the need to continuously monitor their quality and their inclusion in the appropriate cluster.

5. The identification of potentials for the sustainable treasuring Landscape Elements of agricultural landscape with compatible activities is made with the tools of intuitive $\backslash$ heuristic logical frameworks typical of business. The subsequent testing of the original intuition, i.e. the analysis of potential targets respectively agricultural, commercial, recreational and tourist, and the resulting regional impacts, will be carried out in the future research with statistical and econometric tools of Microeconomics (potential) and Regional Macroeconomics (impacts).

\section{Case study}

The methodology has been tested in a specific Case Study in one of the most surprising Landscape area of Calabria: the so-called "Costa Viola Landscape Unit (UdP)", already known to the poet Boccaccio (Fig. 3).

The expected result is an extensive survey and classification of Landscape Elements (Fig. 4).

Case Study looks for a prior treasuring program and plan.

Priorities of conservation and enhancement are derived adopting the multi-dimensional valuation able to perform the above specified comparative assessment of Landscape Elements, deriving their general quality ranking (Fig. 5). Consequent actions are planned on the basis of the Landscape Element ranking, and progressively classified as:

- protection of Elements with the highest value;

- conservation of high value Elements;

- treasuring of other parts within the " Costa Viola Landscape Unit (UdP)";

- development of the remaining urban settlements. 


\section{Prevailing Landscape Element: vineyard terracing}

The relevant inventory of resources has confirmed the persistence of characterizing Landscape Element: i.e. the "Costa Viola vineyard terracing". They are characteristic and typical terracing on the cliffs of the coast, from zero to 300 meters above sea level. For over a millennium they have been an extreme case of "heroic viticulture" and "heroic lemon trees". This has typically played a multifunctional role since it has both carried out an economic function and at the same time as a geo-morphological and hydraulic stabilizer of the slope. For a thousand year the vineyard terracing has been made of dry stone walls. The overall impressive length is estimated to be over a thousand kilometers, and has made it possible to start a high quality wine production characterized by the wine known as "Costa Viola". Their areal extension has been gradually reduced overtime from 1940 to present. Furthermore, it has been carried out an analytical verification through a synoptic quantitative and comparative reading of the current aerial photo (2011 coverage), with two parallel highly detailed Topographic Maps. The latter has been produced by the Italian Military Geographic Institute (IGMI), in 1959 and 1993 respectively. These maps allowed to detect a significant reduction in acreage of vineyard terraces.

\section{First actions and conclusions}

Spatial information and integrated multi criteria analysis and valuation tool (MCA) represent a decision support system in "landscape valuation, preservation, treasuring, planning".

The availability of such a system provides decision makers with the ability to focus on the most significant landscape values, mitigating further urbanization in the highly sensitive areas.

The integrated valuation MCA system estimates the density of landscape values and processes the hierarchical comparative ranking of each Landscape Elements within homogeneous categories. It provides society, actors, stake-holders, and decision-makers with important information about most important Landscape Elements ("relevant" and "prevalent") on which focus the enhancement. So then these "prevalent" Elements will pull into the treasuring cluster other elements that are less attractive.

Research has, so far, performed Landscape Element comparative ordinal valuation using a long time tested DRM approach and algorithm [14]. It has been detected the need for a further MCA algorithm, more powerful as well as spatialized within the SGV and the GeoDataBase framework. In the future, research will focus on built-up the new valuation system McaGis to be within future Case Study, and used to compare the results with those of the AHP and DRM systems, testing if there is a substantial and significant convergence of their hierarchical ranking.

Research performed applicative Case Study in the Costa Viola Landscape Unit.

After a thorough Landscape Element census, taxonomization, valuation, the age-old "vineyard terracing" is indicated by the MCA as the first in the rank, therefore as the most interesting and "prevalent" element in the area. A coordinated enhancement action has been designed and valuated. It started from the revitalization of the typical wine production, encouraged by the continuing success in the world of the Italian high-quality enology. Action integrated, coordinated and connected:

-the first Landscapes Element of the rank order ("vineyard terracing");

-the dense and intense palimpsest of cultural and environmental assets (none of which is as extensive and significant as "vineyard terracing") of the Costa Viola Landscape Unit;

-conventional as well as innovative tourism activities.

The designed connection made possible a system of economic actions which in fact represent a spatial "ecological-museum": landscape; wine; culture; summer tourist conventional activities.

Protection, ecological conservation, agricultural production, cultural tourism can therefore be arranged to be "ecological-museum" in a synergistic way through the "landscape planning".

It has been finally activated on the network an experimental "landscape forum" as a point of meeting between public-private actors to foster cooperation between citizens, municipalities, provinces, regions and national government and trigger a more fervent participation in the cognitive processes related to growing knowledge and census of Landscape Elements (Fig. 6). 


\section{Figures}

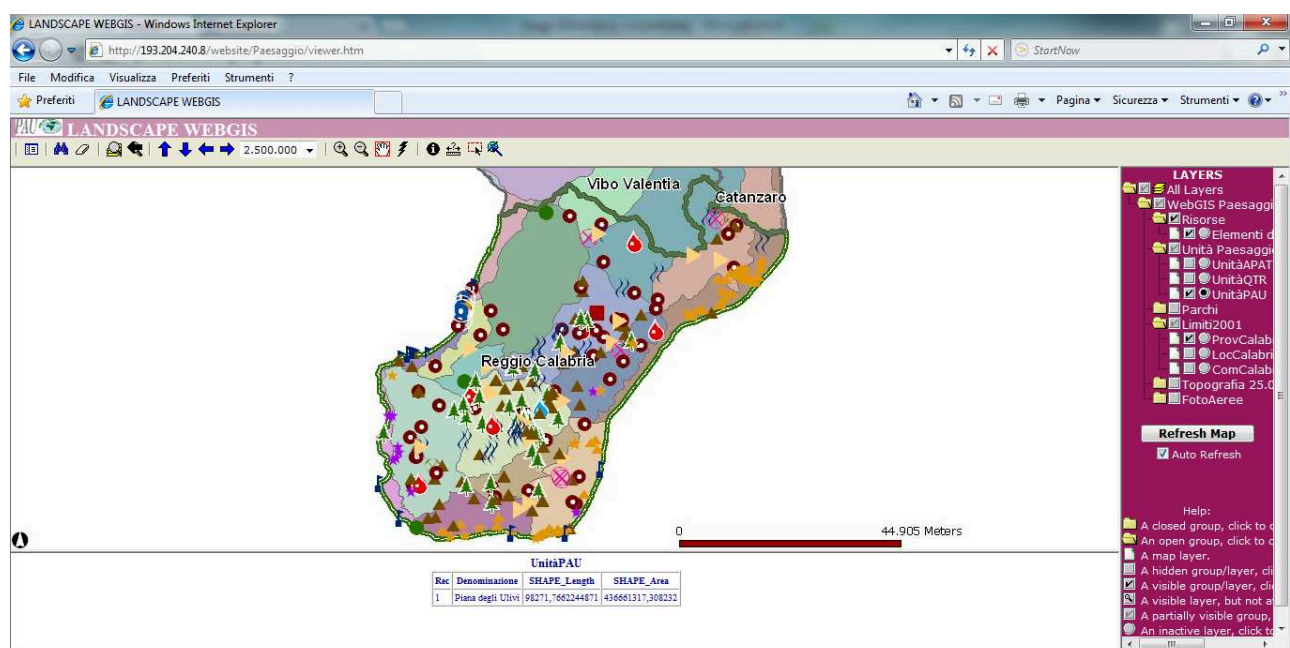

Fig. 1, Province of Reggio Calabria. Landscape Elements. Categories. Total census in GeoDataBase

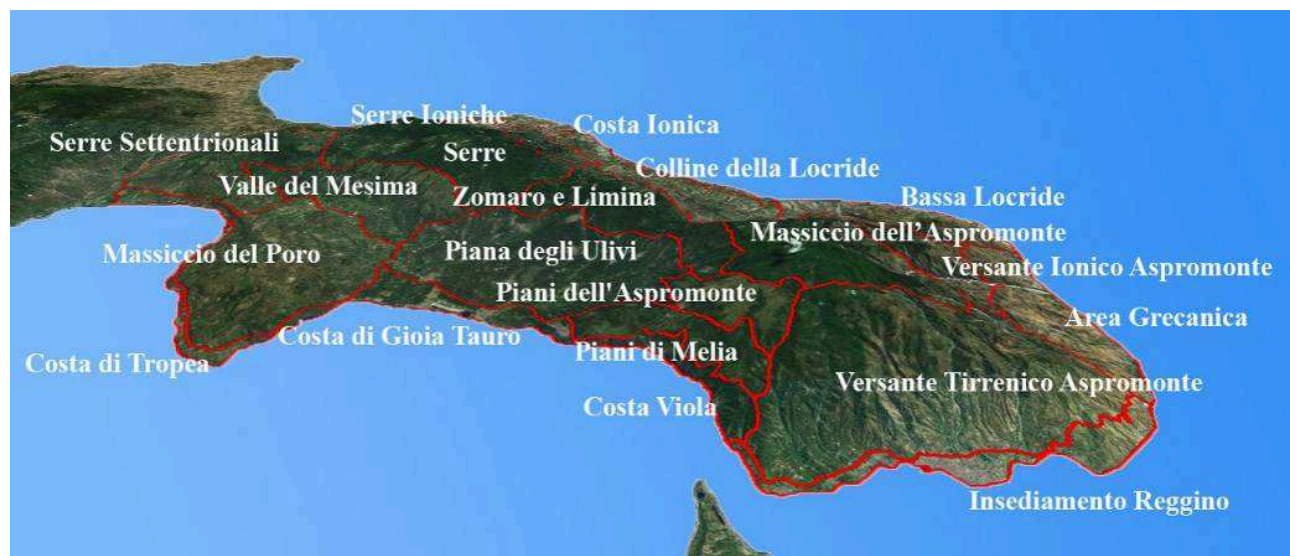

Fig. 2, Provinces of Reggio Calabria and Vibo Valentia. Mega 3D in GeoDataBase. Landscape Units. Singling out

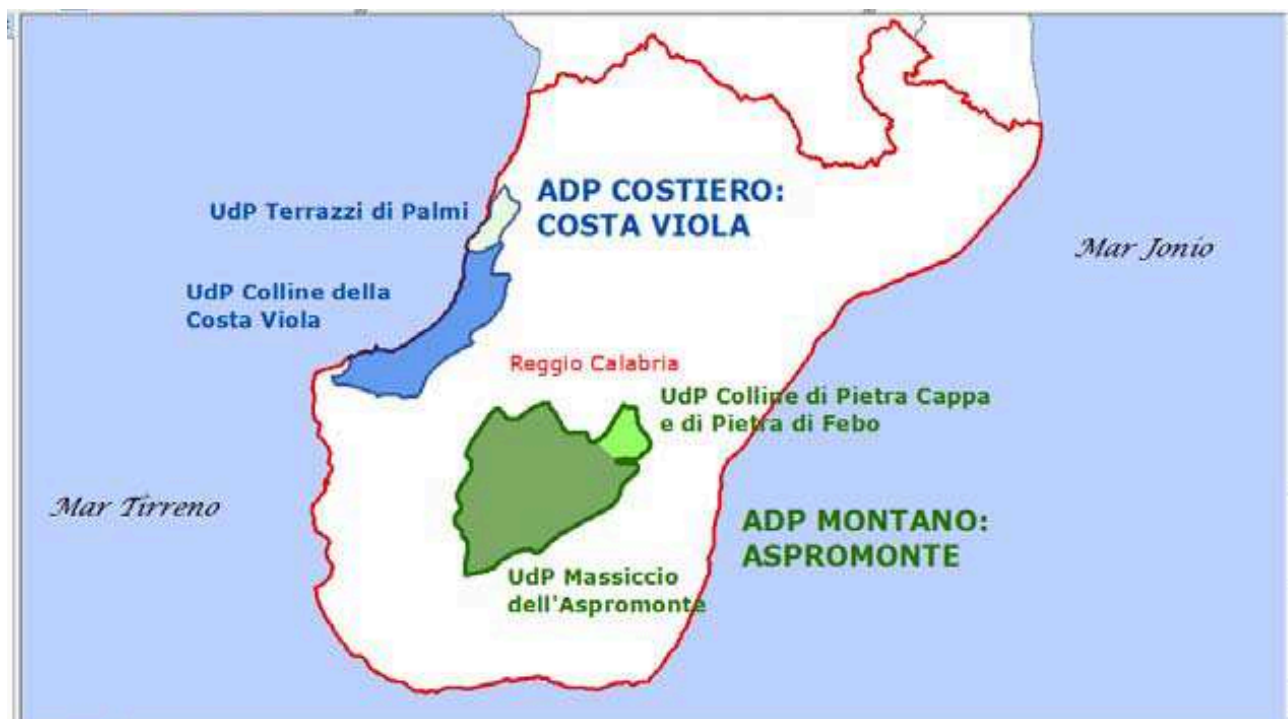

Fig 3, Province of Reggio Calabria. Landscape Areas and Units. Case Study. Comparison between "Costa Viola vineyard terracing" Unit and "Palmi terracing" Unit 


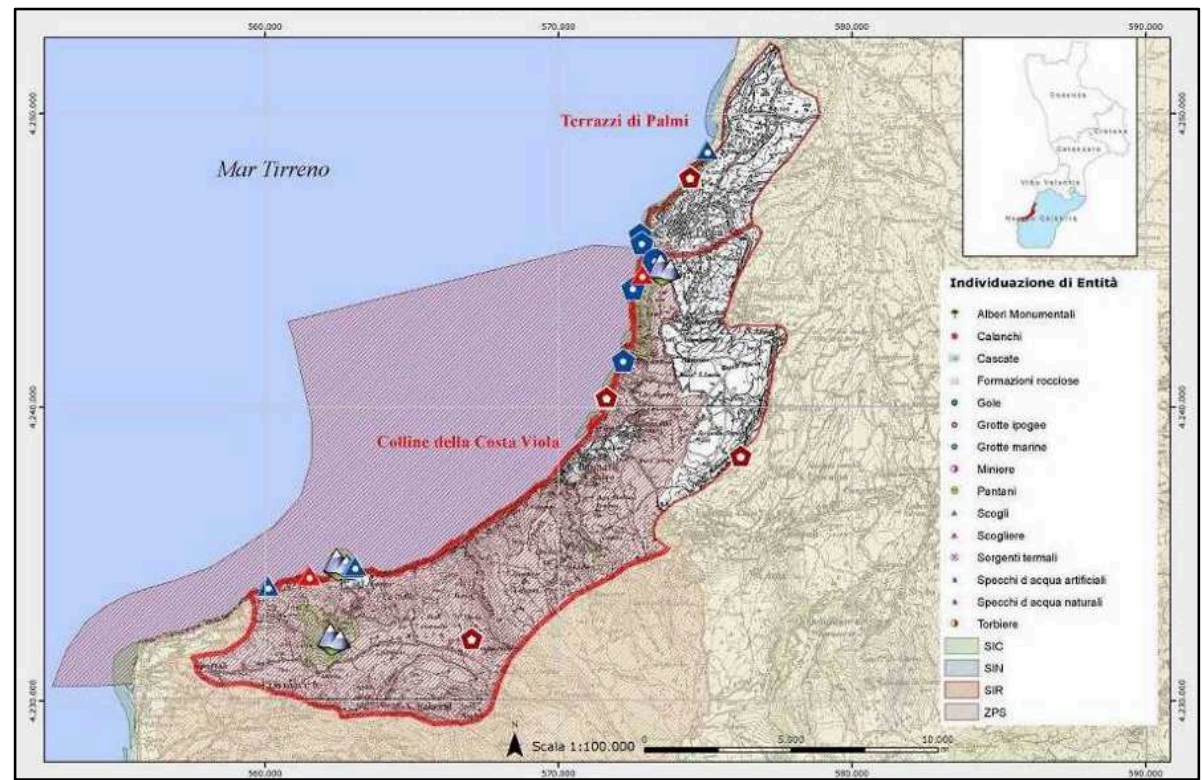

Fig. 4, Costa Viola Landscape Area. "Costa Viola vineyard terracing" Unit and "Palmi terracing" Unit. Landscape Elements. Total census in GeoDataBase

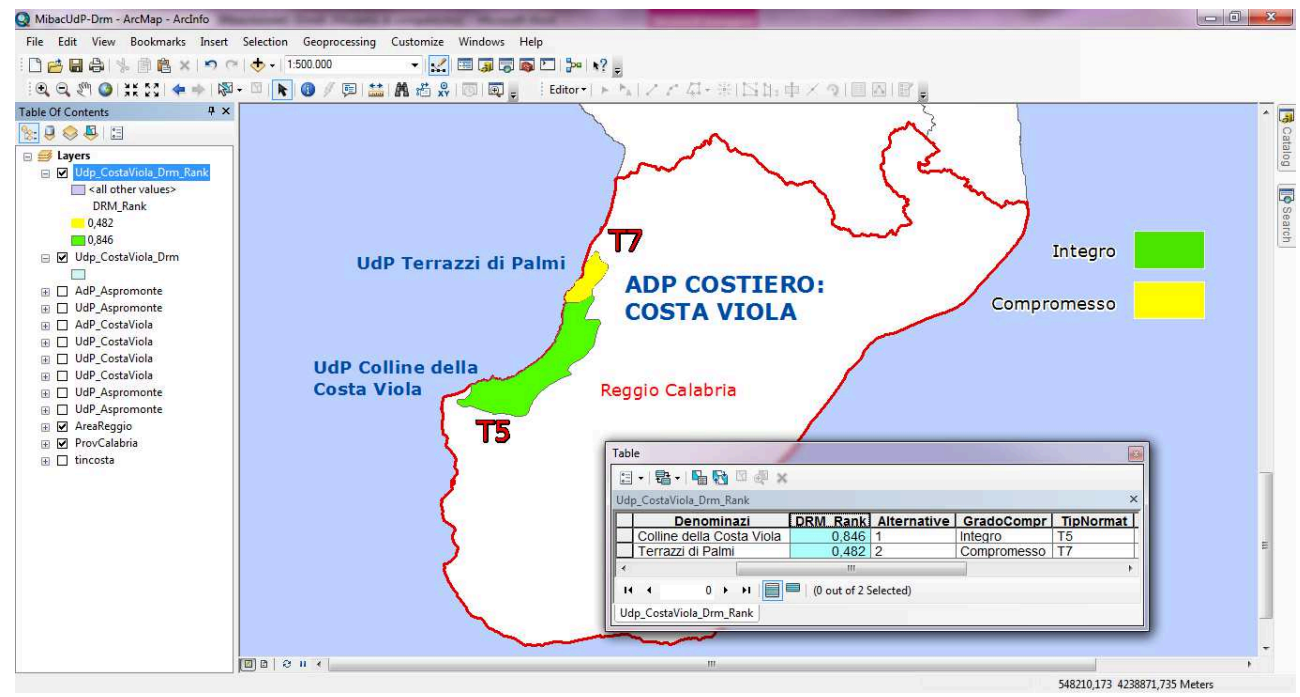

Fig. 5, Costa Viola Landscape Area. "Costa Viola vineyard terracing" Unit and "Palmi terracing" Unit. Intrinsic value density given by ranking and number of Landscape of Elements. Unit ranking in GeoDataBase

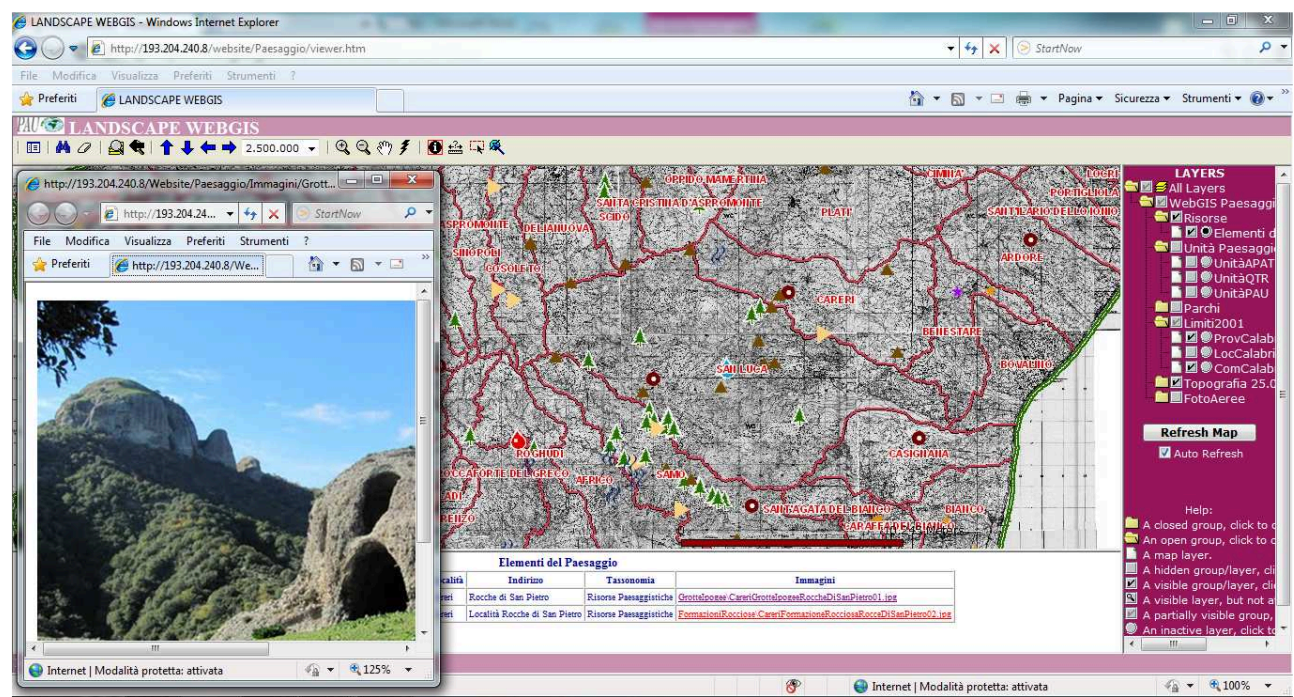

Fig. 6, Province of Reggio Calabria. Landscape Elements. WebGis for general knowledge and evaluation of Landscape Elements 


\section{References}

[1] D. E. MASSIMO set up the research and authored paragraphs 2, 5, 6. M. MUSOLINO authored paragraphs 4 and 9. A. BARBALACE set up the General Information System for Valuation and appraisal (SGV), coordinated the operational research, authored paragraph 1 and 7. C. FRAGOMENI set up the link between SGV and the Case Study and authored paragraphs 3 and 8.

[1] D. E. Massimo: Valuation of Urban Sustainability and Building Energy Efficiency. A Case Study. In: International Journal of Sustainable Development, Vol. 12, (2009)

[2] P. Nijkamp, F. Bal, F. Medda: A survey of methods for sustainable city planning and cultural heritage management. In: European Union Commission, Raphael Programme, Rome. Mimeo (1999)

[3] P. Nijkamp, R. Vreeker: Sustainability Assessment of Development Scenarios: Methodology and Application to Thailand. In: Ecological Economics, n. 33,(2000), pp. 7-27

[4] D. E. Massimo, A. Barbalace: Urban sprawl e crescita economica territoriale. La sfida della scala in una stima a livello sub-regionale. In: Atti della XXX Conferenza Italiana di Scienze Regionali, AISRe. Federalismo, integrazione europea e crescita regionale. Firenze, 0911.09.2009. AISRe, Milano. CD-Rom. (2009a)

[5] D. E. Massimo, A. Barbalace: Valutazione dell' urban sprawl e strumenti GIS. In: Asita (ed): Federazione delle Associazioni Scientifiche per le Informazioni Territoriali ed Ambientali. Asita, Milano, Vol. II: pp. 1399-1404. ISBN 978-88-903132-2-6. (2009b)

[6] D. E. Massimo et alii.: GIS dello sprawl urbanistico. Recenti innovazioni nelle stime quantitative. In: Atti della Dodicesima Conferenza Nazionale Utenti ESRI. GIS in action. Roma, 2728.05.2009. ESRI Italia, Roma. CD-Rom. (2009)

[7] D. E. Massimo, M. Musolino, A. Barbalace: Urban sprawl e valutazione di infrastrutture di trasporto. Un Caso di Studio nell'area centrale della Calabria. In: Marone E. (ed): La Valutazione degli Investimenti Infrastrutturali Urbani ed Extraurbani. Aspetti Giuridici, Estimativi ed Ambientali. Firenze University Press, Firenze. ISSN: 1826-249X. (2010)

[8] D. E. Massimo, A. Barbalace, A. P. P. Massimo, R. M. Cefalà: Valutazione a criteri multipli di alternative di trasporto per fronteggiare lo sprawl. In: Marone E. (ed): La valutazione degli investimenti pubblici per le politiche strutturali. Firenze University Press, Firenze (2011)

[9] S. Stanghellini (ed): La selezione dei progetti e il controllo dei costi nella riqualificazione urbana territoriale. Alinea Editrice, Firenze (2004), pp. 217-242

[10]D. E. Massimo, M. Musolino, A. Barbalace: Uno strumento integrato economico-urbanistico per il governo territoriale di area vasta. Il Sistema Generale di informazione per la Valutazione, SGV. Un caso applicativo. In: Marone E. (ed): Area vasta e governo del territorio. Nuovi strumenti giuridici, economici ed urbanistici. Firenze University Press, Firenze (2006), pp. 91148

[11]P. Nijkamp: Culture and Region: a multidimensional evaluation of monuments. In: Environment and Planning $B$, n. 15, (1988), pp. 5-15

[12] J. Rothenberg: Lectures of the Course 1.1485-14.111J: Economics of Project Evaluation. Dep. of Civ. Eng. and Dep. of Econ., Massachusetts Institute of Technology, Cambridge, MA (on magnetic tapes) (1990)

[13] T. L. Saaty: The Analytic Hierarchy Process: Planning, Priority Setting, Resource Allocation. McGraw-Hill International Book Company. New York. ISBN 0-07-054371-2 (1980) 
[14]E. Hinloopen: De Regime Methode. Doctoraalscriptie Interfaculteit Actuariaat en Economie. Vrije Universiteit, Amsterdam. 25 April 1985. Mimeo (1985)

[15]E. Hinloopen, P. Nijkamp: Regime-methode voor ordinale multicriteria-analyses; Een beschouwing en een commentaar. [Regime-method for ordinal multicriteria analysis; an evaluation and a critique] Rev. Kwantitatieve Methoden, 22, (1986), pp. 61-78

[16]E. Hinloopen, P. Nijkamp: Qualitative multiple criteria choice analysis. The Dominant Regime Method. In: Quality and Quantity, 24, (1990), pp. 37-56 